\title{
Proteolytic Enzyme Engineering: A Tool for Wool
}

\author{
Rita Araújo, ${ }^{\dagger, \ddagger \S}$ Carla Silva, ${ }^{\dagger, \S}$ Raul Machado, ${ }^{\dagger, \ddagger}$ Margarida Casal, ${ }^{*, \neq}$ António M. Cunha," \\ José Carlos Rodriguez-Cabello, ${ }^{\perp}$ and Artur Cavaco-Paulo ${ }^{\S}$ \\ CBMA (Centre of Molecular and Environmental Biology), Department of Biology, University of Minho, \\ Campus of Gualtar 4710-057 Braga, Portugal, 2C2T (Centre of Science and Textile Engineering), \\ Department of Textile Engineering, University of Minho, Campus of Azurém, 4800-058 Guimarães, \\ Portugal, Department of Polymer Engineering, University of Minho, Campus de Azurém, 4800-058 \\ Guimarães, Portugal, and BIOFORGE Research Group, Dpto. Física de la Materia Condensada, E.T.S.I.I., \\ Universidad de Valladolid, Paseo del Cauce s/n, 47011 Valladolid, Spain
}

Received March 10, 2009; Revised Manuscript Received May 4, 2009

\begin{abstract}
One of the goals of protein engineering is to tailor the structure of enzymes to optimize industrial bioprocesses. In the present work, we present the construction of a novel high molecular weight subtilisin, based on the fusion of the DNA sequences coding for Bacillus subtilis prosubtilisin E and for an elastin-like polymer (ELP). The resulting fusion protein was biologically produced in Escherichia coli, purified and used for wool finishing assays. When compared to the commercial protease Esperase, the recombinant subtilisinE-VPAVG 220 activity was restricted to the cuticle of wool, allowing a significant reduction of pilling, weight loss and tensile strength loss of wool fibers. Here we report, for the first time, the microbial production of a functionalized high molecular weight protease for controlled enzymatic hydrolysis of wool surface. This original process overcomes the unrestrained diffusion and extended fiber damage which are the major obstacles for the use of proteases for wool finishing applications.
\end{abstract}

\section{Introduction}

The morphology of wool is highly complex, not only at the fiber stem but also at the surface. It is, in fact, the surface morphology that plays a major role in the wool processing for textile industry. Unwanted effects such as shrinkage, felting, and limited diffusion of dyes and other finishing compounds are most probably due to the presence of wool scales at the fiber surface. ${ }^{1}$ These scales must be removed for an efficient finishing and to provide resistance to felting and shrinkage. Chlorine oxidation is conventionally used, but loss of fabric strength and negative ecological impact precludes its acceptability. ${ }^{2,3}$ There have been several attempts to replace this chlorine process by proteases to degrade scales providing wool with antifelting and antishrinkage characteristics. ${ }^{4,5}$ However, enzymatic reactions need to be controlled to avoid undesirable effects, especially enzyme diffusion into wool cortex and consequent fiber damage. In principle, unrestrained diffusion problems may be overcome increasing protease molecular weight by chemical modification. ${ }^{6-8}$ Chemical modification relates to an alteration of chemical structure and can be conducted by cross-linking of protease with glutaraldehyde or by the attachment of synthetic polymers like polyethylene glycol. ${ }^{6-8}$ However, due to the presence of residual free enzyme, wool degradation still occurs, though to a less extent. ${ }^{8}$

In the present work, we engineered, produced and characterized a subtilisin E fused with an elastin-like polymer (ELP), resulting in a high molecular weight recombinant protein. The

\footnotetext{
* To whom correspondence should be addressed. Tel.: +351 253604310 . Fax: +351253 678980. E-mail: mcasal@bio.uminho.pt.

Authors contributed equally to this work.

CBMA.

\&2C2T.

"Department of Polymer Engineering.

${ }^{\perp}$ BIOFORGE Research Group.
}

ELP gene used is based on 220 repetitions of the monomeric sequence VPAVG, previously constructed in our laboratory. ${ }^{9}$

Subtilisin E from Bacillus subtilis, is first synthesized as a prepro-subtilisin with the 29 amino acid residues presequence serving as a signal peptide for secretion from the cell. Upon cleavage of the presequence, the prosubtilisin $\mathrm{E}$ undergoes cleavage either autocatalytically or by existing active subtilisin $\mathrm{E}$ to produce active mature enzyme. ${ }^{10}$ Based on literature data, our ELP polymer sequence is not a substrate for subtilisin E..$^{11,12}$

Here we compare the behavior of two proteases, the commercially available low molecular weight Esperase, and the recombinant high molecular weight subtilisinE-VPAVG ${ }_{220}$, in the diffusion and hydrolytic attack to wool fibers.

\section{Materials and Methods}

Bacterial Strains, Plasmids, and Enzymes. The Escherichia coli strain BL21(DE3), the T7 plasmid pET25b (+) and Overnight Express Instant TB medium were purchased from Novagen (Madison WI). Restriction and modification enzymes were from Roche Applied Science (Germany). The commercial enzyme used in this study was the protease Esperase (E.C.3.4.21.62) from Sigma-Aldrich. Unless specifically stated, all the other reagents were from Sigma-Aldrich (St. Louis MO).

Wool Material. Untreated pure wool woven fabrics and yarns of $23 \mu \mathrm{m}$ (mean diameter) were provided by Albano Antunes Morgado Lda, Portugal.

Gene Synthesis. The DNA coding for the peptide monomer containing 10 repetitions of VPAVG was chemically synthesized and subjected to concatenation. The multimeric block genes (flanked by Eam1104I recognition sites) were obtained by directional ligation in the cloning vector pDrive (Qiagen, Hilden, Germany), resulting in the construction pDrive: $\mathrm{VPAVG}_{220}$. Construction was confirmed with the restriction enzymes Eam1104I and EcoRI (Fermentas, St. Leon-Rot, Germany). This strategy was previously described and reported as the "Gutenberg Method". 13,14 The construction pDrive-VPAVG 220 was digested with $M b o I I$. The fragment MboII-VPAVG $220-M b o I I$ was 

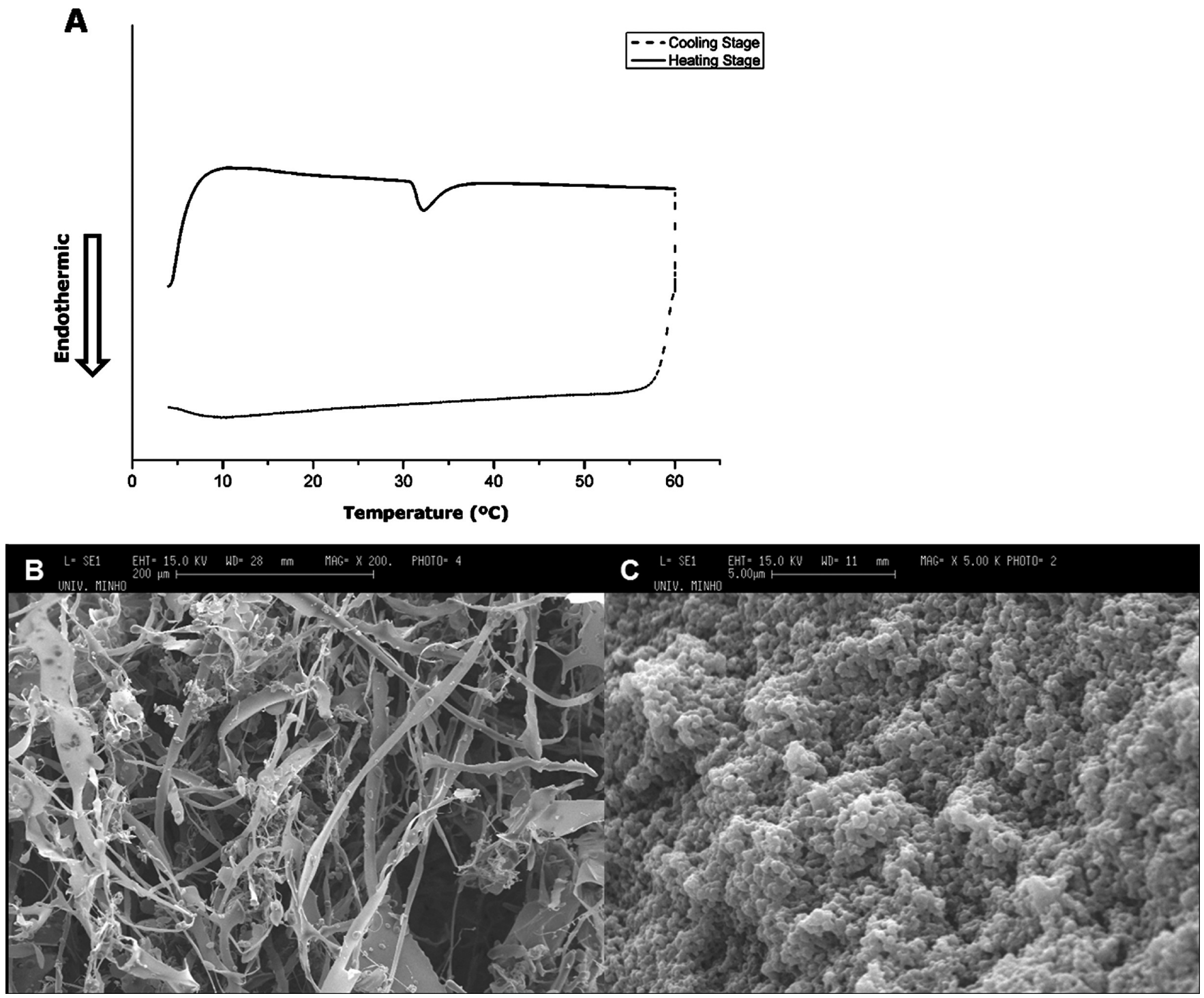

Figure 1. (A) DSC run with $25 \mathrm{mg} / \mathrm{mL}$ subtilisinE-VPAVG 220 solution in water. (B) SEM image showing the disordered state of lyophilized subtilisinE-VPAVG 220 before the particle preparation (see Materials and Methods), below the $T_{\mathrm{t}}$. (C) SEM image showing the size and shape of aggregates formed during the particle preparation (see Materials and Methods) above the $T_{\mathrm{t}}$.

Klenow blunted and purified from a $1 \%(\mathrm{w} / \mathrm{v})$ agarose gel electrophoresis. After DNA extraction, the gene was cloned into the XhoI digested, Klenow blunted, and dephosphorilated pET25b:prosubtilisinE, ${ }^{15}$ resulting in the final construction pET25:prosubtilisinE$\mathrm{VPAVG}_{220}$. This vector was used to transform E. coli strain XL1 Blue, according to the Simple and Efficient Method. ${ }^{16}$ The plasmid construct was verified by restriction analysis with $L g u \mathrm{I}$ and by DNA sequencing, following the method of Sanger ${ }^{17}$ using an ABI PRISM 310 Genetic Analyzer. DNA cloning and manipulation were performed according to the standard protocols. ${ }^{18}$ The recombinant plasmids were then transformed into the expression strain E. coli BL21(DE3) (Novagen).

Protein Expression and Purification. A single colony of $E$. coli BL21(DE3) harboring pET25:prosubtilisinE-VPAVG 220 was inoculated at $30{ }^{\circ} \mathrm{C}$, overnight, in Novagen Autoinduction medium, containing $100 \mu \mathrm{g} / \mathrm{mL}$ ampicillin. Cells were harvested by centrifugation at 3000 $\times \mathrm{g}$ for $10 \mathrm{~min}$, washed with phosphate buffered saline solution (PBS; $10 \mathrm{mM} \mathrm{Na} 2 \mathrm{HPO}_{4}, 2 \mathrm{mM} \mathrm{KH} \mathrm{PO}_{4}, 137 \mathrm{mM} \mathrm{NaCl}, 3 \mathrm{mM} \mathrm{KCl}, \mathrm{pH}$ 7.4), and lysed by ultrasonic disruption. Ultrasonic treatment was performed at 120 Watts with a $25 \mathrm{~mm}$ probe in an Ultrasonic Processor GEX400. Four 2 min pulses, with 2 min on ice between each pulse, were performed. Cellular lysate was centrifuged at $15400 \times \mathrm{g}$ for 30 min at $4{ }^{\circ} \mathrm{C}$. Supernatant was reserved for protein purification and the pellet, insoluble debris, was resuspended in PBS and reserved for analysis by sodium dodecyl sulfate-polyacrylamide gel electrophoresis
(SDS-PAGE). Recombinant protein was purified using an immobilized metal affinity chromatography (IMAC) system with a HisPrep FF 16/ 10 column (GE Healthcare) already prepacked with precharged $\mathrm{Ni}$ Sepharose 6 Fast Flow. Column equilibration was performed with 10 $\mathrm{mM}$ imidazole, $0.5 \mathrm{M} \mathrm{NaCl}$, and $20 \mathrm{mM}$ phosphate buffer, $\mathrm{pH}$ 7.6. Samples were applied onto the column at a flow rate of $2 \mathrm{~mL} / \mathrm{min}$. Elution was performed with a buffer containing $80 \mathrm{mM}$ imidazole, 0.5 $\mathrm{M} \mathrm{NaCl}$, and $20 \mathrm{mM}$ phosphate buffer, pH 7.6.

Protein Electrophoresis and Protease Activity. Proteins were detected by SDS-PAGE using a Tris-SDS-glycine buffer system. ${ }^{19}$ SDS PAGE gel images were acquired with Molecular Imager ChemiDoc XRS system and Quantity One software from Biorad. Protein detection was done by Coomassie Brilliant Blue R250. Protease activity of commercial Esperase and recombinant subtilisinE-VPAVG 220 was measured using casein as substrate. ${ }^{6}$ One unit of activity is defined as the amount of enzyme that hydrolyses casein to produce equivalent color to $1 \mu \mathrm{mol}$ of Tyrosine, per minute, at $\mathrm{pH} 7.5$ and $37{ }^{\circ} \mathrm{C}$ (color by the Folin and Ciocalteu's reagent). Target protein concentration was determined by a modification of the micro Lowry method ${ }^{20}$ using bovine serum albumin as standard and using Sigma test kit no. P5656.

Differential Scanning Calorimetry (DSC). DSC experiments of subtilisinE-VPAVG 220 were performed on a Mettler Toledo DSC822 $2^{\mathrm{e}}$. Liquid nitrogen was used as cooler and the calibration of enthalpy and temperature was performed with indium (In) and zinc ( $\mathrm{Zn})$. The analyses 

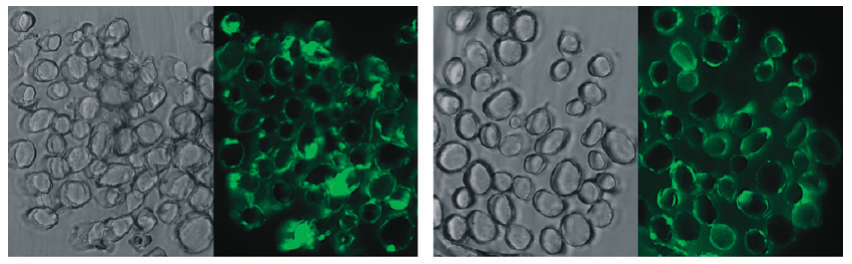

A B

Figure 2. Fluorescence microscopy images of fiber cross sections of wool yarns treated with FITC-labeled commercial Esperase $(A)$ and recombinant subtilsinE-VPAVG $220(B ; 100 \times)$.

were carried with $25 \mathrm{mg} / \mathrm{mL}$ of subtilisinE-VPAVG 220 in deionized water. In a typical DSC run, $25 \mu \mathrm{L}$ of polymer solution were placed in a hermetically sealed aluminum pan and studied under a four-stage thermal program. First, the sample was pretreated $15 \mathrm{~min}$ at $4{ }^{\circ} \mathrm{C}$, followed by a heating stage (HS) from 4 to $60{ }^{\circ} \mathrm{C}$ with a constant heating rate of $+10{ }^{\circ} \mathrm{C} / \mathrm{min}$. The sample was maintained at $60{ }^{\circ} \mathrm{C}$ for $3 \mathrm{~min}$ and cooled down in a cooling stage $(C S)$ to $4{ }^{\circ} \mathrm{C}$ with a constant cooling rate of $-10{ }^{\circ} \mathrm{C} / \mathrm{min}$. The onset value was calculated with the provided STARe software.

Preparation and Morphological Characterization of SubtilisinEVPAVG $_{220}$ Particles. A solution of $5 \mathrm{mg} / \mathrm{mL}$ of subtilisinE-VPAVG 220 in water was treated at $50{ }^{\circ} \mathrm{C}$ over $40 \mathrm{~min}$. Particles were formed by polymer self-aggregation from aqueous solution. The solution was then centrifuged at $16000 \times \mathrm{g}$ and the supernatant was discarded. The pellet was finally dried at $37^{\circ} \mathrm{C}$ overnight.

Fluorescein Isothiocyanate (FITC) Linkage to Proteins. Enzymes were linked to FITC (100/1, w/w) in sodium carbonate buffer, pH 8.5. Free FITC was removed using HiTrap desalting columns (Amersham). Wool samples were incubated in each of these solutions at $37^{\circ} \mathrm{C}$ and $20 \mathrm{rpm}$, for $24 \mathrm{~h}$. Wool fibers cross sections were analyzed on a Leica Microsystems DM-5000B epifluorescence microscope with appropriate filter settings using a $100 \times$ oil-immersion objective. Images were acquired with a Leica DCF350FX digital camera and processed with LAS AF Leica Microsystems software.

Enzymatic Treatment of Wool Yarns. Before enzymatic treatment, wool yarns were subjected to two different pretreatments: Scouring (S): wool was washed with $1 \mathrm{~g} / \mathrm{L}$ of surfactant Lutensol AT 25 (BASF, Germany) in a bath ratio of 1:20 at pH $9.0\left(\mathrm{Na}_{2} \mathrm{CO}_{3} 0.1 \mathrm{M}\right.$ and $\mathrm{NaHCO}_{3}$ $0.1 \mathrm{M}$ buffer) for $30 \mathrm{~min}$ at $40{ }^{\circ} \mathrm{C}$ in a Rotawash machine. The surfactant was removed from wool first with tap water, followed by distilled water. Bleaching ( $\mathrm{S}+\mathrm{B})$ : after scouring, wool was immersed in a bath with $1 \%$ (of weight of fabric) $\mathrm{H}_{2} \mathrm{O}_{2}$ at $\mathrm{pH} 9.0\left(\mathrm{Na}_{2} \mathrm{CO}_{3} 0.1 \mathrm{M}\right.$ and $\mathrm{NaHCO}_{3} 0.1 \mathrm{M}$ buffer) for $1 \mathrm{~h}$ at $55^{\circ} \mathrm{C}$ in a Rotawash machine. Enzymatic treatment was performed in plastic tubes containing $0.5 \mathrm{~g}$ of wool yarns, subjected to the different pretreatments described above and $0.85 \mathrm{U}$ of commercial or recombinant protease in $50 \mathrm{~mL}$ of 0.01 $\mathrm{M}$ phosphate buffer solution ( $\mathrm{pH}$ 7.6). The tubes were incubated at 37 ${ }^{\circ} \mathrm{C}$ and $90 \mathrm{rpm}$ in a shaking water bath for $24 \mathrm{~h}$. Several controls were run simultaneously: a control test wool without pretreatment (control), a control test with surfactant washed wool (control, S) and a control test with bleached wool (control, S + B), all without protein. After incubation, wool yarns were removed and washed with Lutensol AT 25 and water for tensile strength, felting, and pilling evaluation.

Enzymatic Treatment of Wool Fabrics. Woven fabrics of $100 \%$ wool were scoured using a procedure identical to that used for wool yarns but in liquor to fiber ratio of 1:100. The fabrics were rinsed with tap water followed by distilled water. Enzymatic treatment of scoured wool fabrics was performed with $0.85 \mathrm{U}$ of commercial or recombinant protease in $0.3 \mathrm{M}$ Tris- $\mathrm{HCl}$ buffer with $0.03 \mathrm{M} \mathrm{CaCl}_{2}, \mathrm{pH}$ 7.6. Treatments were conducted at $50{ }^{\circ} \mathrm{C}$ and $70 \mathrm{rpm}$ (orbital agitation) for $5 \mathrm{~h}$. After incubation, wool fabrics were removed and washed. The remaining solution was centrifuged and the amount of amino acids produced was measured in terms of tyrosine equivalents. ${ }^{21}$

Weight Loss. Wool fabrics were dried at $50{ }^{\circ} \mathrm{C}$ for $2 \mathrm{~h}$, desiccated and weighted until constant weight (considered as differences between successive weights inferior to $1 \mathrm{mg}$ ). The measurements correspond to two independent assays carried out in duplicate.

Tensile Strength and Shrinkage. Tensile strength resistance of yarns was determined using a Tensile Tester Machine, accordingly to ASTMD5035-90. Fabric tensile strength was determined using a P2000 Burst Strength Tester. All the samples were conditioned before testing in a standard atmosphere. The tensile strength resistance values are given as the mean of an $n \geq 10$ replicates, together with the standard deviation (the coefficient of variation was below $10 \%$ for all cases). Wool fabric shrinkage was determined after five 5A wash cycles according to Woolmark method TM31.

Felting and Pilling. Felting and pilling of yarns were visually evaluated after repeated washing $(3 \times)$ at $50{ }^{\circ} \mathrm{C}$, for $60 \mathrm{~min}$ and 20 $\mathrm{rpm}$. For wool fabrics, samples were weighted and immediately placed in a Pilling Box Machine type P.T.2 (Testrite Ltd., West Yorkshire, England). The right sides of the samples were abraded under longabrasion cycles (18000) following BS 5811:1986. Fabric samples were

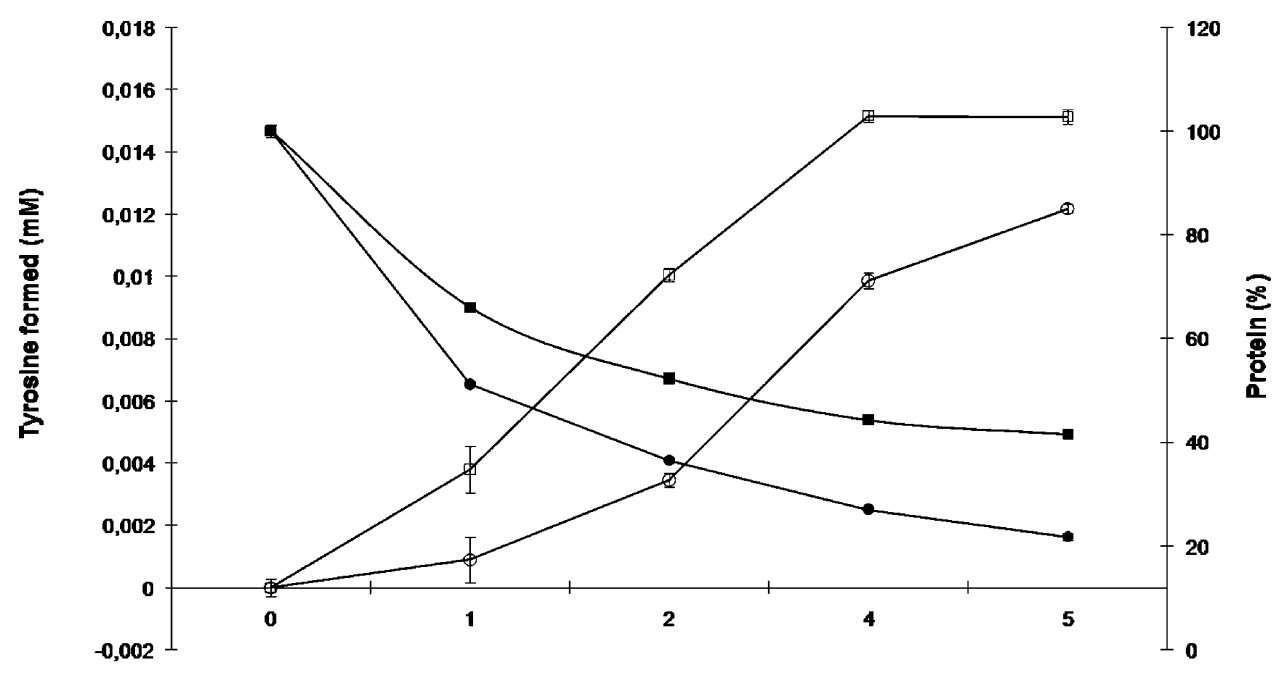

Time (hours)

Figure 3. Formation of tyrosine (mM; open symbols) and total protein (\%; closed symbols) for the enzymes Esperase ( $\mathbf{\square}$, $\square$ ) and subtilisinE$\operatorname{VPAVG}_{220}(\bullet, 0)$. Release of free tyrosine is directly related to activity of the protease. Mean values of tyrosine formation were significantly different compared with the subtilisinE-VPAVG $220, p<0.001$. 


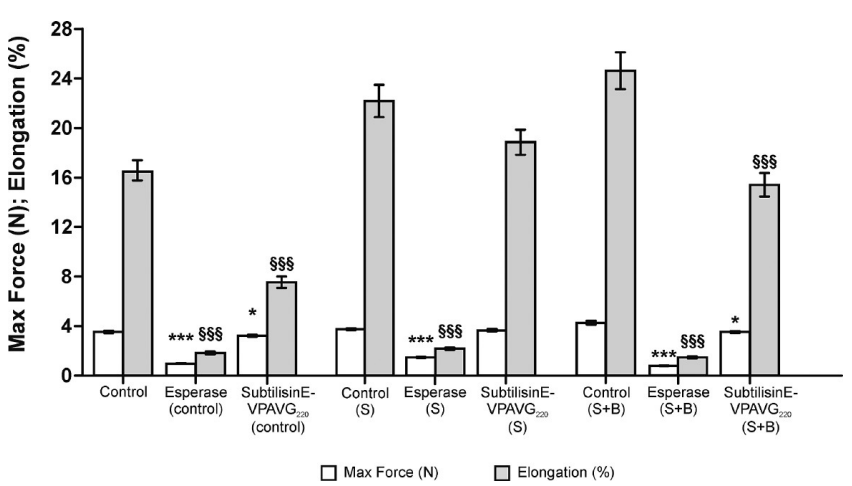

Figure 4. Maximum tensile strength ( $N$ ) and elongation (\%) supported by wool yarns subjected to different pretreatments treated with the commercial Esperase and recombinant subtilisinE-VPAVG 220 .
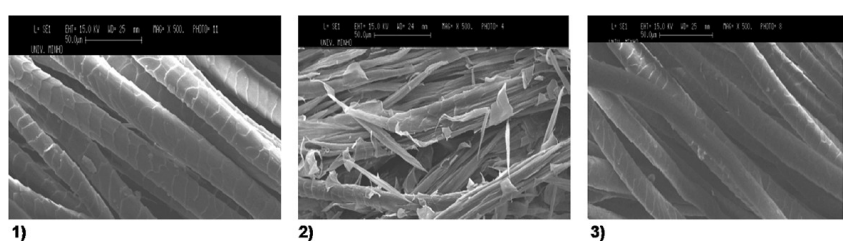

Figure 5. SEM microphotographs of wool fabrics after the treatments: (1) control; (2) Esperase; (3) genetically modified subtilisinE$\mathrm{VPAVG}_{220}$.

then rated by visual estimation according to the International Standard ISO12945-2. Samples were compared with standard fabrics rated from 1 to 5 , where one indicates the highest level of pill density.

Statistical Analysis. Data are expressed as means with standard errors of the means (SE). A repeated measures ANOVA followed by the Tukey's post hoc test (GraphPad Prism 5.0 for Windows) was employed to compare the effect of Esperase and subtilisinE-VPAVG 220 in the formation of tyrosine with matched observations for time. In all the other experiments One Way ANOVA was used. $P$ values $<0.05$ were considered statistically significant.

\section{Results and Discussion}

Protein Expression and Purification. Escherichia coli BL21(DE3) transformants carrying pET25:prosubtilisinE$\mathrm{VPAVG}_{220}$ grown and induced at $30{ }^{\circ} \mathrm{C}$ successfully expressed the recombinant enzyme at high levels in the soluble fraction (see Supporting Information, Figure 1A). The SDS-PAGE analysis of the cellular lysate revealed the presence of a soluble protein with a molecular weight greater than $116 \mathrm{kDa}$. In our previous work we were not able to obtain native subtilisin $\mathrm{E}$ in soluble fraction using the same expression system, ${ }^{15}$ which suggests that the ELP fused with subtilisin E is acting as a solubility tag, allowing the expression of soluble and processed active enzyme (see Supporting Information, Figure 1C). This finding allowed us to recover the recombinant enzyme in the soluble fraction with no need of further solubilization and renaturation steps. The different approaches of protein solubilization, such as urea treatment, apart from being timeconsuming do not guarantee the yield of proteins with native and active conformation. Thus, the strategy developed in this work can also contribute to the production of other valuable proteins that cannot be expressed using conventional E. coli expression methodologies.

The obtained recombinant protein was efficiently purified by metal-affinity chromatography and used for wool treatment experiments (see Supporting Information, Figure 1B).
Differential Scanning Calorimetry (DSC) Analysis and Morphological Characterization by Scanning Electron Microscopy (SEM). DSC analysis was used for the determination of the transition temperature that was expected to occur upon heating the sample. In the thermogram obtained during the heating stage (HS; Figure 1A), the presence of an endothermic peak is clearly evident which, in the range of the temperatures analyzed, is the only thermal component of the curve and is associated with the characteristic process of chain folding and self-aggregating of ELPs. ${ }^{13}$ The transition temperature $\left(T_{\mathrm{t}}\right)$ or temperature for self-assembling is identified with the onset value of the peak and was calculated as approximately $31^{\circ} \mathrm{C}$ for the subtilisinE-VPAVG 220 . These results are consistent with data previously observed for a chemically synthesized poly(VPAVG), where a $T_{\mathrm{t}}$ of approximately $30^{\circ} \mathrm{C}$ was found. ${ }^{22}$ These results led us to speculate that the $\mathrm{VPAVG}_{220}$ chain is conformationally free in the subtilisinE-VPAVG 220 construction and that the contribution arising from the subtilisin $\mathrm{E}$ amino acid chain into the aggregation process and, thus, influencing the $T_{\mathrm{t}}$ is minimal.

During the polymer cooling stage, reported in the lower curve of Figure 1, the beginning of a sole exothermic component is present around $10^{\circ} \mathrm{C}$, which is related to the dissolution of the aggregates and rehydration of the polymer. ${ }^{13}$

Upon subtilisinE-VPAVG 220 purification by temperature shifts, the formation of a compact and dense structure is noticed when heating the sample at $50{ }^{\circ} \mathrm{C}$. After centrifugation and drying of the assembled polymer the sample turned into a stiff compact structure. Figure 1 shows SEM micrographs of lyophilized/dehydrated polymer below (B) and above (C) the $T_{\mathrm{t}}$. Below the $T_{\mathrm{t}}$ the polymer appears in an essentially disordered state, with structures resembling fibers. Above the $T_{\mathrm{t}}$, the difference is quite evident as the polymer self-aggregates into compact sphere-like structures quite similar to a previously described VPAVG polymer. ${ }^{13,22}$ This fact suggests that the chimeric protein assembles into microstructures through its elastin domain and free subtilisin $\mathrm{E}$ active domains.

Wool Enzymatic Treatment. In general, native subtilisins have a molecular mass of approximately $30 \mathrm{kDa}$, which is the major drawback on their application for wool treatment. Due to their relatively small size, the enzymes can diffuse into the fiber cortex causing the degradation of the internal parts of wool structure. Based on literature, we postulated that an increase greater than 4-fold on subtilisin E molecular weight would prevent diffusion of enzyme into wool. ${ }^{7,8}$ A total of $0.85 \mathrm{U}$ of both commercial and recombinant enzymes were fluorescently labeled with a fluorescent dye, FITC, and yarns were incubated in these solutions for $24 \mathrm{~h}$. The yarns were entrapped in a nonfluorescent resin and sliced in thin layers with a microtome. Fluorescence microscopy images show that FITC labeled Esperase penetrated in some wool yarns due to heterogeneous nature of wool fiber, while the enlarged recombinant subtilisinE$\mathrm{VPAVG}_{220}$, having a molecular weight above $116 \mathrm{kDa}$, appeared to remain at the surface of yarns (Figure 2A,B).

Silva and collaborators have obtained similar results after chemical modification of subtilisin with PEG and Eudragit S-100. ${ }^{7,8}$ The chemically modified enzymes presented molecular weights greater than $97 \mathrm{kDa}$ which were effective to limit the hydrolysis only at the wool cortex. ${ }^{7,8}$ Fluorescence microscopy results provided a good indication that recombinant subtilisinE$\mathrm{VPAVG}_{220}$ effect is mainly restricted to wool's surface.

The wool fiber's cuticle is covered by a covalently bound lipid layer, responsible for the high hydrophobicity of wool. Alkaline pretreatments can partially remove some of these lipids, 
Table 1. Effect of Enzymatic Treatment on Wool Fabric Shrinkage and Resistance Determined in Terms of Weight Loss and Maximum Pressure Supported by Samples

\begin{tabular}{lccr}
\hline \multicolumn{1}{c}{ sample } & shrinkage $(\%) \pm \mathrm{SE}^{a}$ & weight loss $(\%) \pm \mathrm{SE}$ & pressure $(\mathrm{kPa}) \pm \mathrm{SE}$ \\
\hline control & $6.1 \pm 0.13$ & $6.1 \pm 0.37$ & $519.4 \pm 4.43$ \\
Esperase & $2.5 \pm 0.00^{b, d}$ & $18.4 \pm 0.64^{e, g}$ & $11.1 \pm 1.66^{h, i}$ \\
subtilisinE-VPAVG & $5.8 \pm 0.09^{f, g}$ & $513.5 \pm 6.25^{i}$ & \\
\hline
\end{tabular}

${ }^{a}$ Mean values of shrinkage were significantly different compared with the respective control. ${ }^{b} P<0.001 .{ }^{c} P<0.01$ and between the two enzymatic treatments. ${ }^{d} P<0.001$. Mean values of weight loss were significantly different compared with the respective control group. ${ }^{e} P<0.001,{ }^{f} P<0.05$ and between the two enzymatic treatments. ${ }^{g} P<0.01$. Mean values of pressure were significantly different compared with the respective control. ${ }^{h} P<0.001$ and with the subtilisinE-VPAVG $220 .{ }^{i} P<0.001$.

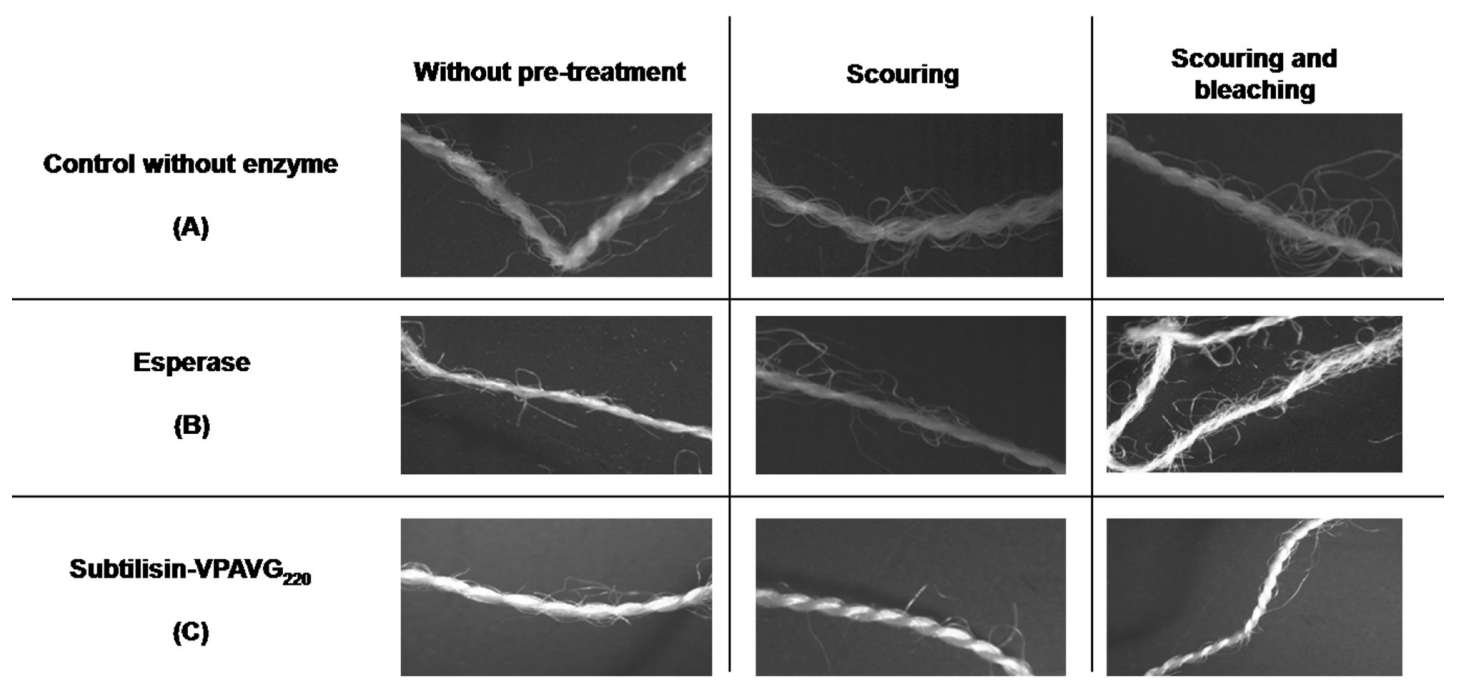

Figure 6. Visual damage on wool yarns after three cycles washing in a Rotawash machine. (A) Wool yarns without enzyme; (B) wool yarns treated with commercial Esperase; and $(C)$ wool yarns treated with subtilisinE-VPAVG 220 .

reducing its hydrophobic nature and simultaneously enhancing protein diffusion inside the fiber. ${ }^{23}$ Wool yarns were therefore subjected to two alkaline pretreatments, a scouring washing (S), and a scouring washing followed by bleaching $(S+B)$. Wool yarns previously pretreated were incubated with $0.85 \mathrm{U}$ of either Esperase or subtilisinE-VPAVG 220 for $24 \mathrm{~h}$ for tensile strength resistance evaluation. Regarding scoured wool fabrics, the enzymatic treatment was performed using the same amount of enzyme units for $5 \mathrm{~h}$ under orbital agitation.

Enzymatic hydrolysis of wool fabrics was determined in terms of tyrosine equivalents (Figure 3 ). When the proteases digest wool, the amino acid tyrosine is released along with other amino acids and peptide fragments. Folin's reagent primarily reacts with free tyrosine to produce a blue colored chromophore, which is quantifiable and measured as an absorbance value on the spectrophotometer. The more tyrosine that is released from wool, the more the chromophores are generated and the stronger the activity of the protease. Absorbance values generated by the activity of the Esperase and the recombinant enzyme are compared to a standard curve to correlate changes in absorbance with the amount of tyrosine released. The subtilisinE-VPAVG 220 showed very low release of tyrosine into the media. Comparing to commercial Esperase, the amount of aminoacids produced in tyrosine equivalents was significantly higher ( $p$ $<0.001$ for all time points), indicating wool fiber degradation by the enzyme.

These results were also corroborated by the determination of resistance in terms of tensile strength and elongation of the samples. The maximum tensile strength supported by wool yarns (Figure 4) and fabrics (Table 1) was drastically lower for samples treated with Esperase, which promoted more than $50 \%$ of reduction in the original samples tensile strength, indicating higher fiber degradation as a consequence of enzyme diffusion. Wool yarns incubated with $0.85 \mathrm{U}$ of subtilisinE-VPAVG 220 retained maximum tensile strength comparable to those of control samples (without enzyme). Because the high molecular weight subtilisinE-VPAVG 220 is retained at the surface of wool yarns with no diffusion of enzyme inside the fibers, only the cuticle is under proteolytic attack, which can explain the higher tensile strength of samples after enzymatic treatment.

Elongation values, displayed a high variability among the different pretreatments. The parameter elongation is the ability of the fiber to undergo deformation. Different studies have reveal that the increase of the elongation of fiber wool after scouring or scouring and bleaching treatments, keeping the original resistance values, can be considered a normal behavior. Mild conditions of scouring and bleaching, like we have used in our experiments, can remove salt links and break the disulfide crosslinks, making the wool fiber easier to extend. ${ }^{1}$ This fact explains why the elongation values display a high extent of variability among the control and subtilisinE-VPAVG 220 samples. This effect is not observed in Esperase-treated samples where, due to the decrease of resistance, almost no elongation is observed before breaking the yarns.

Wool fabrics were also subjected to felting shrinkage tests $(5 \times 5 \mathrm{~A}$ wash cycles). Control samples (no enzymatic treatment) presented a shrinkage area greater than $6 \%$. The antishrinkage effect of Esperase (only 2.5\% of shrinkage area) is quite obvious and higher than antishrinkage effect induced by recombinant subtilisinE-VPAVG 220 (5\%) when comparing both with the control samples (Table 1). However, the antishrinkage effect cannot be analyzed alone, as an independent characteristic. Together with antishrinkage characteristics, weight loss and resistance of fabrics are desirable properties that must be retained in terms to meet consumer's demands. This overall effect is 
achieved only when the recombinant enzyme is used. The main differences between enzymatic treatments were observed in the fabric resistance, as mentioned above, as well as in the weight loss.

Wool fabrics treated with $0.85 \mathrm{U}$ of commercial Esperase present the highest weight loss (more than 18\%) compared to samples treated with the same units of recombinant subtilisinE$\mathrm{VPAVG}_{220}$, which induced considerably less damage to the wool fabric (in the order of $9 \%$, respectively, for the same conditions; Table 1). The damages observed in control samples (weight losses of $6 \%$ ) are due to the agitation promoted during samples incubation for $5 \mathrm{~h}$ at $50{ }^{\circ} \mathrm{C}$. High levels of mechanical agitation associated with high temperature lead to some degree of fabric damage and consequently to weight loss. The enzymatic degradation of wool fibers by Esperase was quite significant. This enzyme is able to penetrate into wool cortex and catalyze different components of wool fibers. As shown in Figure 5, the fibers suffered much less damage when the enzymatic treatment was performed using the increased molecular weight enzyme, meaning that the impact of degradation can be controlled by the conditions of treatment. The fibers that were not degraded had their cuticle layer removed, thus, improving their textile properties.

To evaluate the damage of enzymatic treatment on wool yarns, samples pretreated as previously described, and incubated with both enzymes, were washed for three consecutive cycles in a Rotawash machine. Pilling was visually evaluated (Figure 6).

Regarding the damage induced by enzymatic treatment on wool fabrics, samples were subjected to 18000 cycles of abrasion in a Pilling Box Machine. Pilling was visually evaluated and rated from 1 to 5 .

Both pretreatments seemed to induce a slight degree of damage on wool yarns. This degradation was more extensive when commercial Esperase was used. Wool fabrics treated with Esperase also presented a higher level of felting and pilling (Level 1) than samples treated with recombinant subtilisinE$\mathrm{VPAVG}_{220}$ (Level 4, data not shown).

In fact, samples treated with subtilisinE-VPAVG 220 felted even less than the control samples (Level 1 of felting and pilling, data not shown), which emphasizes the idea that, due to its size, the hydrolytic activity of subtilisinE-VPAVG 220 is restricted to the surface of wool fibers, and that the elastomeric polymer $\mathrm{VPAVG}_{220}$ can provide protection of yarns and fabrics against excessive damage.

\section{Conclusions}

Enzymes can play an important role in the development of novel technologies for wool finishing bioprocesses at an industrial level. In particular, modified proteases have been described as a promising alternative for wool finishing, because they can represent an effective way of removing wool scales and can be an ecological option to the conventional chlorine treatments. ${ }^{6-8}$

In this work, we have attained the production of a recombinant high molecular weight subtilisin $\mathrm{E}$ for wool finishing through the fusion of subtilisin E gene with a sequence coding for an elastin-based polymer. The interest in the application of these polymers in diverse areas of industry is continuously growing. This new class of materials has many advantages over the conventional petroleum-based polymers: they can be obtained by chemical synthesis and by recombinant DNA technology involving gene construction, Escherichia coli transformation and expression by fermentation. ${ }^{24,25}$
The effect of recombinant high molecular weight subtilisinE$\mathrm{VPAVG}_{220}$ was first assessed on wool yarns and subsequently on wool fabrics, and compared to the effect of commercial Esperase. As expected, due to its small size, Esperase was able to penetrate inside the wool cortex, damaging the fiber. In contrast, the subtilisinE-VPAVG 220 hydrolyzed just the cuticle layer of wool. Both yarns and fabrics treated with engineered enzyme presented higher tensile strength and lower felting and pilling, along with lower weight loss, as well as better dyeing. Recombinant enzyme seems also to impart wool fabrics shrinkage resistance properties.

Although this study clearly illustrates the potential advantage in using the protein-based polymer $\mathrm{VPAVG}_{220}$ for functionalization of subtilisin $\mathrm{E}$ for wool finishing, the approach used in this investigation can be further optimized. For example, thermally responsive elastin-based polymers like $\mathrm{VPAVG}_{220}$ undergo an inverse phase transition. Below their inverse transition temperature $\left(T_{\mathrm{t}}\right.$; near $30{ }^{\circ} \mathrm{C}$ for $\left.\mathrm{VPAVG}_{220}\right)$ ELPs are structurally disordered, highly solvated, and thus, soluble in aqueous solutions; above $T_{\mathrm{t}}$, the polymer gradually precipitates as a consequence of the formation of intramolecular contacts between nonpolar regions. ${ }^{26-28}$ Therefore, $\mathrm{VPAVG}_{220}$ can be used not only to functionalize subtilisin $\mathrm{E}$ by increasing its molecular weight, but the reversible soluble-insoluble phase transition behavior of this polymer can also be exploited to develop a simple and nonchromatographic method for purification of the recombinant subtilisinE-VPAVG 220 . This method of purification of ELP fusion proteins has previously been reported and termed inverse transition cycling (ITC). ${ }^{29,30}$ Using this method, the recombinant subtilisinE-VPAVG 220 can be selectively purified from other $E$. coli proteins by sequential and repeated cycles of aggregation, centrifugation, and resolubilization of recombinant protein. ${ }^{26}$ The ranges of temperatures that can be employed for an efficient subtilisinE-VPAVG 220 purification, without irreversible denaturation of the fusion protein, are currently being investigated. After optimization, this procedure can easily be scaled up to accommodate larger culture volumes, making this technique highly competitive against any conventional chromatographic process.

Overall, we have developed a new high molecular weight subtilisinE-VPAVG 220 , which represents a breakthrough in wool finishing treatment, promising as an ecological alternative to the traditional highly polluting Chlorine/Hercosett treatment, used in textile industry.

In addition, nowadays detergent enzymes account for $89 \%$ of the total protease sales in the world and a significant share of the market is captured by subtilisins from Bacillus species. The new recombinant enzyme produced by our work group can be included in new detergent formulations that can be used to wash all kinds of garments, including silk and wool.

Acknowledgment. This work was supported by EU funding project Enzup-Enzymatic Up-grading of Wool Fibres 2005032877, by ElastM Project, POCI/CTM/57177/2004 from Fundação para a Ciência e Tecnologia (Portugal), "Junta de Castilla y Leon" (VA087A06, VA016B08, and VA030A08), MEC (MAT2007-66275-C02-01 and NAN2004-08538), and by the Marie Curie RTN Biopolysurf (MRTN-CN-2004005516). Raul Machado received a Ph.D. Grant SFRH/BD/ 36754/2007 from Fundação para a Ciência e Tecnologia (Portugal). The authors would like to thank Magda Graça (CBMA) for all the technical support in sequencing.

Supporting Information Available. Figure S1: SDS-PAGE of (A) soluble fraction of E. coli BL21(DE3) transformed 
with pET25b:prosubtilisinE-VPAVG 220 and (B) purified subtilisinE-VPAVG 220 . The solid arrows indicate the position of recombinant protein. (C) Schematic representation of prosubtilisinE-VPAVG 220 processing into the mature active form subtilisinE-VPAVG 220 . This material is available free of charge via the Internet at http://pubs.acs.org.

\section{References and Notes}

(1) Negri, A. P.; Cornell, H. J.; Rivett, D. E. Text. Res. J. 1993, 63 (2), 109-115.

(2) Schlink, T.; Greeff, J. Farming Ahead 2001, 118, 58-59.

(3) Shen, J.; Bishop, D. P.; Heine, E.; Hollfelder, B. J. Text. Inst. 1999, 90 (3), 404-411.

(4) Levene, R.; Cohen, Y.; Barkai, D. J. Soc. Dyers Colour. 1996, 112 (1), 6-10.

(5) Parvinzadeh, M. Enzyme Microb. Technol. 2007, 40 (7), 1719-1722.

(6) Silva, C. J. S. M.; Sousa, F.; Gübitz, G.; Cavaco-Paulo, A. Food Technol. Biotechnol. 2004, 42 (1), 51-56.

(7) Silva, C. J. S. M.; Prabaharan, M.; Guebitz, G.; Cavaco-Paulo, A Enzyme Microb. Technol. 2005, 36 (7), 917-922.

(8) Silva, C. J. S. M.; Zhang, Q.; Shen, J.; Cavaco-Paulo, A. Enzyme Microb. Technol. 2006, 39 (4), 634-640.

(9) Machado, R.; Ribeiro, A. J.; Padrão, J.; Silva, D.; Nobre, A.; Teixeira, J. A.; Arias, F. J.; Cunha, A. M., Rodríguez-Cabello, J. HC.; Casal, M. J. Nano Res. 2009, submitted for publication.

(10) Power, S. D.; Adams, R. M.; Wells, J. A. Proc. Natl. Acad. Sci. U.S.A. 1986, 83 (10), 296-310.

(11) Morihara, K.; Tsuzuki, H. Arch. Biochem. Biophys. 1969, 129 (2), 620-634.

(12) Morihara, K.; Oka, T.; Tsuzuki, H. Arch. Biochem. Biophys. 1970, 138 (2), 515-525.
(13) Rodríguez-Cabello, J. C.; Reguera, J.; Girotti, A.; Alonso, M.; Testera, A. M. Prog. Polym. Sci. 2005, 30 (11), 1119-1145.

(14) Girotti, A.; Reguera, J.; Rodríguez-Cabello, J. C.; Arias, F. J.; Alonso, M.; Testera, A. M. J. Mater. Sci.: Mater. Med. 2004, 15 (4), 479-484.

(15) Araújo, R.; Cavaco-Paulo, A.; Casal, M. Eng. Life Sci. 2008, 8 (3), $1-3$.

(16) Inoue, H.; Nojima, H.; Okayama, H. Gene 1990, 96 (1), 23-28.

(17) Sanger, F.; Nicklen, S.; Coulson, A. R. Proc. Natl. Acad. Sci. U.S.A. 1977, 74 (12), 5463-5467.

(18) Sambroock, J.; Russel, D. W. Cold Spring Harbor Laboratory, 3rd ed.; Cold Spring Harbor: New York, NY, 2001.

(19) Laemmli, U. K. Nature 1970, 277 (5259), 680-685.

(20) Lowry, O. H.; Rosenberg, W. J.; Farr, A. L.; Randell, R. J. J. Biol. Chem. 1951, 193 (1), 265-275.

(21) Hull, M. E. J. Dairy Sci. 1947, 30 (11), 881-884.

(22) Herrero-Vanrell, R.; Rincón, A. C.; Alonso, M.; Reboto, V.; MolinaMartinez, I. T.; Rodríguez-Cabello, J. C. J. Controlled Release 2005, 102 (1), 113-122.

(23) Brack, N.; Lamb, R.; Pham, D.; Turner, P. Colloids Surf., A 1999, $146(1-3), 405-515$.

(24) Tirrell, D. A.; Fournier, M. J.; Mason, T. L. MRS Bull. 1991, 16 (7), $23-28$.

(25) U.S. Congress, Office of Technology Assessment, Biopolymers: Making Materials Nature's Way, Background Paper, OTA-BP-E-102; U.S. Government Printing Office: Washington, DC, 1993.

(26) Meyer, D. E.; Chilkoti, A. Nat. Biotechnol. 1999, 17 (11), 1112-1115.

(27) Li, B.; Alonso, O. V.; Daggett, V. J. Mol. Biol. 2001, 305 (3), 581592.

(28) Li, B.; Daggett, V. Biopolymers 2003, 68 (1), 121-129.

(29) Banki, M. R.; Feng, L.; Wood, D. W. Nat. Methods 2005, 2 (9), 659661.

(30) Trabbic-Carlson, K.; Liu, L.; Kim, B.; Chilkoti, A. Protein Sci. 2004, 13 (12), 3274-3284.

BM9002943 